\title{
New Horizons in the Treatment of Cartilaginous Pathology beyond Conservative Secondary Prevention
}

\section{Wegrecki KJ ${ }^{1^{*}}$, Sadig $\mathbf{R}^{1}$ and Kurpik $A^{2}$}

${ }^{1}$ School of Medicine, University of Notre Dame Sydney, Australia

${ }^{2}$ Department of Medicine, Pomeranian Medical University Szczecin, Poland

\section{Editorial}

Cartilage has traditionally been considered an inert tissue that develops in the early years and subsequently loses its capacity for repair and remodeling. Hence, all but the mildest injuries and degenerative conditions affecting the cartilage of joints have traditionally been treated conservatively with a view to reduce further harm and postpone the inevitable onset of symptoms rather than healing. Although these strategies remain the mainstay of treatment, cell and growth factor based therapies have recently shown great promise in the treatment of cartilaginous injuries and degenerative joints.

In this month's issue of the Journal of Physiotherapy and Physical Rehabilitation, we would like to report on new possibilities in adjunct therapies that do not yet have wide currency and would benefit from further research and circulation.

Intra-articular injections of platelet-rich plasma (PRP) have been demonstrated to provide relief and improve function in osteoarthritis of the knee $[1,2]$. Activation of the PRP leads to the release of growth factors from the a-granules in the platelet cytoplasm. These growth factors have been associated with the initiation of a healing cascade that leads to cellular chemotaxis, angiogenesis, synthesis of collagen matrix, and cell proliferation [3]

As PRP has gained traction, some researchers have already considered combining this with other additives, such as growth hormone, which has shown to be promising [4].

Most studies have focused on injecting knee joints and hips, however, a new horizon is the extension of this treatment modality to other joints, such as the articulations of the spinal column. Pettine et al. [5] found that injection of autologous bone marrow aspirate was effective as an alternative to surgical vertebral fusion in reducing discogenic back pain.

A paucity of published, randomized, controlled trials precludes us from evaluating the efficacy of these treatment modalities. Furthermore, it is uncertain if and how rehabilitation programs ought to be modified in patients receiving these adjunct treatments by physical therapists and rehabilitation specialists. As evidence mounts in favour of cell and growth factor based therapies, further research should be directed to studying whether combination with physical therapy modalities can further improve outcomes.

This strategy, of course, presumes a simple mechanical model for the development of lower back pain. Recent studies have suggested alternate causes of intervertebral disc herniation and degeneration, such as infectious and inflammatory processes.

Albert et al. [6] found improvement in lower back pain after long-term antimicrobial therapy, providing strong support for a role of Propionebacterium acnes in lumbar spondylosis. Others have also found a high prevalence of microorganisms in extruded disc material $[7,8]$. Lest anyone doubt the plausibility of this hypothesis, Chen et al.
[9] have been able to demonstrate P. acnes as a causative factor in an animal model.

A new-found association between aquaporin-1 expression and lumbar disk herniation has also been discovered [10]. This offers researchers a new avenue for investigation regarding the aetiology of intervertebral disk herniation symptoms.

These advances in the field of musculoskeletal pathology have the potential to revolutionize the approach to cartilaginous and degenerative conditions in terms of prophylaxis and targeted treatment modalities. Given that more than half of herniated discs will spontaneously resorb [11], the great call for conservative treatments should continue to resound. However, those herniations that remain can cause lasting neurological sequalae if left untreated, which demands rigorous identification of patients that are unlikely to experience improvement without invasive surgical intervention.

\section{References}

1. Cole BJ, Karas V, Hussey K, Merkow DB, Pilz K, et al. (2017) hyaluronic acid versus platelet-rich plasma: a prospective, double-blind randomized controlled trial comparing clinical outcomes and effects on intra-articular biology for the treatment of knee osteoarthritis. Am J Sports Med 45: 339-346.

2. Lana JFSD, Weglein A, Sampson SE, Vicente EF, Huber SC, et al. (2016) Randomized controlled trial comparing hyaluronic acid, platelet-rich plasma and the combination of both in the treatment of mild and moderate osteoarthritis of the knee. J Stem Cells Regen Med 12: 69-78.

3. Wang SZ, Rui YF, Tan Q, Wang C (2013) Enhancing intervertebral disc repair and regeneration through biology: Platelet-rich plasma as an alternative strategy. Arthritis Res Ther 15: 220.

4. Rahimzadeh P, Imani F, Faiz SH, Alebouyeh, MR, Azad-Ehyaei D, et al. (2016) Adding intra-articular growth hormone to platelet rich plasma under ultrasound guidance in knee osteoarthritis: A comparative double-blind clinical trial Anesthesiol Pain Med 6: 41719

5. Pettine K, Suzuki R, Sand T, Murphy M (2016) Treatment of discogenic back pain with autologous bone marrow concentrate injection with minimum two year follow-up. Int Orthop 40: 135-140.

6. Albert HB, Sorensen JS, Christensen BS, Manniche C (2013) Antibiotic treatment in patients with chronic low back pain and vertebral bone edema (modic type 1 changes): A double-blind randomized clinical controlled trial of efficacy. Eur Spine J 22: 697-707.

7. Aghazadeh J, Salehpour F, Ziaeii E, Javanshir N, Samadi A, et al. (2016)

${ }^{*}$ Corresponding author: Kamil J. Wegrecki, School of Medicine, University of Notre Dame Sydney, Australia; Tel: +0423099371; E-mail: kamil.wegrecki1@my.nd.edu.au

Received: January 19, 2018; Accepted: January 23, 2018; Published: January 29, 2018

Citation: Wegrecki KJ, Sadig R, Kurpik A (2018) New Horizons in the Treatment of Cartilaginous Pathology beyond Conservative Secondary Prevention Physiother Rehabil 3: e101. doi: 10.4172/2573-0312.1000e101

Copyright: (c) 2018 Wegrecki KJ, et al. This is an open-access article distributed under the terms of the Creative Commons Attribution License, which permits unrestricted use, distribution, and reproduction in any medium, provided the original author and source are credited. 
Citation: Wegrecki KJ, Sadig R, Kurpik A (2018) New Horizons in the Treatment of Cartilaginous Pathology beyond Conservative Secondary Prevention. Physiother Rehabil 3: e101. doi: 10.4172/2573-0312.1000e101

Page 2 of 2

Modic changes in the adjacent vertebrae due to disc material infection with Propionibacterium acnes in patients with lumbar disc herniation. Eur Spine $J$ 26: 3129-3134.

8. Fritzell P, Bergström T, Welinder-Olsson C (2004) Detection of bacterial DNA in painful degenerated spinal discs in patients without signs of clinical infection. Eur Spine J 13: 702-706

9. Chen Z, Zheng Y, Yuan Y, Jiao Y, Xiao J, et al. (2016) Modic changes and disc degeneration caused by inoculation of propionibacterium acnes inside intervertebral discs of rabbits: a pilot study. Biomed Res Int 2016: 7

10. Hoffman H, Choi AW, Chang V, Kimball J, S Verkman AS, et al. (2017) Aquaporin-1 expression in herniated human lumbar intervertebral discs. Glob Spine J 7: 133-140.

11. Zhong M, Liu JT, Jiang H, Mo W, Yu PF, et al. (2017) Incidence of spontaneous resorption of lumbar disc herniation: A meta-analysis. Pain Physician J 20: 45-52. 